\title{
El proceso de formación de la imagen de gobierno
}

The process of forming a government image

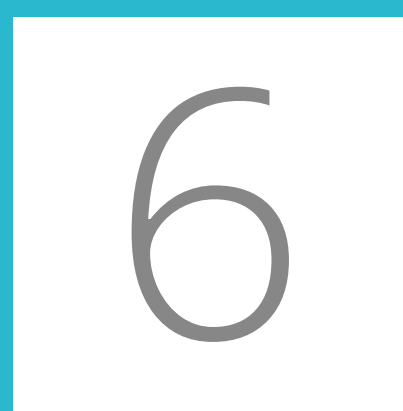

ARTÍCULO

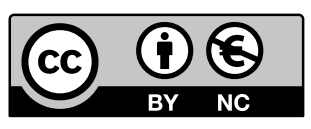

\section{Gustavo Cusot}

Vicedecano del Colegio de Comunicación y Artes Contemporáneas de la Universidad San Francisco de Quito.

Coordinador de la Carrera de Comunicación Organizacional de la Universidad San Francisco de Quito. Comunicador y asesor en el ámbito de la comunicación y la imagen corporativa de empresas e instituciones de Argentina, España, Estados Unidos y Ecuador. Candidato a Doctor en Comunicación en la UNIACC.

gcusot@yahoo.com

ORCID: 0000-0002-8814-9808

Fecha de recepción: 19 de julio de 2018 / Aceptación: 3 de septiembre de 2018

\section{Resumen}

La imagen de un gobierno se construye a partir de varios aspectos que mantenga un Gobierno, y a cada uno de sus actores políticos. El proceso de formación y consolidación de la imagen está compuesta por un importante proceso que abarca tres etapas: En primer lugar, la Identidad de Gobierno, es decir, la esencia de su proyecto político e ideología. Dentro de esta etapa, se analizan los rasgos físicos y culturales de quienes componen a esta Entidad: Presidente, Vicepresidente y funcionarios. En segundo lugar, la Comunicación, tanto lo que dice el gobierno, cómo lo dice y cómo presentan y comercializan sus políticas, tomando en cuenta los diversos aspectos verbales y no verbales. En este sentido, es crucial que la comunicación se maneje de manera planificada y estratégica. A partir de estas dos etapas, los ciudadanos generan una percepción sobre el Gobierno y se construye su Imagen. El éxito de la imagen de un Gobierno es que ésta coincida con la identidad del Gobierno; es decir, que la percepción que tiene los ciudadanos sobre el Gobierno, coincida con la esencia propia del Gobierno.

\section{PALABRAS CLAVE}

Identidad, Comunicación, Estrategia, Imagen, Gobierno, Campaña Política 


\section{Abstract}

Government image is built on several components maintained by the government and each of its political agents. The process of image formation and consolidation is composed of a process in three stages. First, there is the identity of the government, that is, the essence of its political project and ideology. Within this stage, the physical and cultural features of those who make up this entity are analysed: the President, the Vice-President and officials. Secondly, there is communication: what the government says, how it says it and how it presents and markets its policies, taking into account a variety of verbal and non-verbal aspects. It is crucial that communication is managed in a planned strategic manner. O this basis, citizens create a perception of government and its image. A successful image coincides with the identity of the government. That is, the perception that citizens have of the government coincides with the essence of the government.

\section{KEYWORDS}

Identity, communication, strategy, image, government, political campaign

\section{INTRODUCCIÓN}

"En el terreno de la verdad y el conocimiento, quien pretenda erigirse como juez, naufragará bajo la risa de los dioses" Albert Einstein.

Desde tiempos ancestrales, la imagen y la comunicación han estado interrelacionadas y estrechamente anexadas al concepto de poder. Si nos remontamos a la época del imperio egipcio, el faraón, sinónimo de divinidad, mantenía una marcada diferenciación de dominio sobre el resto de la población. Su identidad e imagen estaban construidas con un sinnúmero de atributos, simbologías y modismos que lo realzaban y ayudaban a proyectar una imagen de divinidad y poder, definido como "la capacidad relacional que permite a un actor social influir de forma asimétrica en las decisiones de otros actores sociales de modo que se favorezcan la voluntad, los intereses y los valores del actor que tiene el poder" (Castells y Hernández 2009). Lo mismo ocurrió con la realeza, pues quienes formaban parte de ella, dan muestra de la importancia de la imagen para la distinción, dominio y poder. En ese sentido, Acanda (2003) sostiene que "el estatuto ontológico del poder no es el de un ente objeto, sino el de un complejo sistema de relaciones. El poder es relación de fuerzas. Por lo tanto, no surge después de que se ha estructurado el todo social, sino que es elemento de su conformación" (2003: 115). Con ello podemos afirmar que el poder es un fenómeno social, en donde sociedad y poder interactúan y se reproducen a sí mismos, como parte de expresiones de poder. En ese marco la imagen y la comunicación marcan una diferenciación de dominio y status social. Qué decimos, cómo lo decimos, cómo nos vestimos, cómo nos comportamos, cómo actuamos; son ítems que construyen una imagen específica de una persona, colectivo u organización; los mismos que harán parte, junto con otros aspectos, de la edificación de su identidad.

Lo mismo ocurre en el marco político actual, la imagen puede ofrecer y desplegar poder y protagonismo. En un partido político, la imagen y comunicación figuran como herramientas claves y estratégicas durante todo el proceso de campaña electoral y el período de gobernanza, ya que bajo estos instrumentos recae gran responsabilidad del éxito de la contienda electoral, acceso al poder y por supuesto, una 
adecuada y óptima conservación del partido. Recordemos que la comunicación, en este sentido, no se refiere únicamente a intercambiar información entre emisor y receptor, o reducir distancias; sino que bajo una visión estratégica, es una herramienta poderosa capaz de generar una influencia en la conducta de los ciudadanos votantes y así provocar en ellos familiarización y sentido de pertenencia hacia el candidato político. De esta manera, éste tendrá una mayor probabilidad de éxito en las campañas electorales durante su estancia en el poder e incluso podrá asegurar un cierre positivo de su mandato cuando su período culmine.

Pero, ¿qué es realmente la imagen de gobierno?, ¿bajo qué cimientos se construye una imagen positiva de un actor político?, ¿qué es la comunicación política y cómo se aplica? Si bien la imagen política es un recurso estratégico para posicionar al actor político como el mejor candidato al poder, sin duda es aquí donde los medios de comunicación juegan un papel altamente importante para la construcción de la percepción que se forman los ciudadanos acerca del candidato o gobernante. Por ello, es vital considerar un plan correctamente estudiado y diseñado para atribuir al personaje una comunicación e imagen deseada y que a la realidad social.

El objetivo del presente ensayo es definir los elementos que permiten y determinan el proceso de formación de la imagen de un gobierno, a través del análisis de la identidad y la comunicación como tal. Para ello, se realizarán conceptos partiendo desde un punto de vista corporativo, para, en base a ello, vincularlos y aplicarlos en el marco teórico a nivel de gobierno.

En primer lugar, el presente ensayo enfatizará la definición de imagen y lo que este vocablo contempla, partiendo, como ya se mencionó, del concepto de imagen corporativa. Además, se incorporará aquí la importancia de la interpretación o percepción como tal, y como ésta se genera de diferente forma en cada individuo. Posteriormente, se definirán los elementos que se requieren para la formación de imagen de un gobierno y su importancia y se profundizará en cada uno de ellos. Finalmente, se expondrá cómo la identidad y la comunicación se convierten en atributos claves para la construcción de la percepción e imagen de un gobierno.

\section{De la imagen corporativa a la imagen de gobierno}

Antes de llegar al concepto base de lo que es "imagen de gobierno", me permitiré clarificar el significado de Imagen, pues este es un término muchas veces mal utilizado, y que, por lo tanto, genera confusión al momento de emplearlo. Para ello, nos enfocaremos en el concepto de imagen corporativa, para posteriormente aplicar esta definición a un partido o actor político, sea candidato, presidente y/o funcionario. Paul Capriotti define a la imagen corporativa como "la actitud que tienen los públicos hacia la organización como tal, en cuanto ser vivo, social y comunicativo. Es la idea global que tienen sobre sus productos, sus actividades y su conducta" (1992, pág. 28). Por su parte, Nicholas Ind, señala que "la imagen corporativa no es más que la que un determinado público percibe sobre una organización a través de la acumulación de todos los mensajes que haya recibido" (1992, pág. 6). Asimismo, Joan Costa aporta una interesante definición sobre este término, asegurando que la imagen corporativa es "la representación mental, en el imaginario colectivo, de un conjunto de atributos y valores que funcionan como un estereotipo y determinan la conducta y opiniones de esta colectividad" (2009, pág. 53). Basado en estos conceptos podemos concluir que la imagen de 
gobierno es la representación mental o percepción que tienen los ciudadanos sobre el mismo. Se forma como consecuencia de la interpretación que hacen los ciudadanos según la información que reciben. Ahora bien, cada público, en este caso, cada ciudadano, puede construir su propia representación mental sobre el gobierno. Por ende, la imagen que perciba un ciudadano, puede ser totalmente diferente a la de otro, puesto que cada persona interpreta dependiendo de sus constructos situacionales, sociales, culturales, económicos, etc. Incluso cuando la percepción es originada de un mismo mensaje y a través de un mismo medio o canal.

Dicho a través de un ejemplo: si un presidente joven que está siendo televisado en vivo, expone un breve discurso a la ciudadanía a través de palabras sencillas, claras, y sonreído; generará distintas reacciones de los televidentes. Por un lado, un grupo determinado percibirá al gobernante con una imagen positiva, relacionada con cercanía a la comunidad, familiaridad, carisma, inteligencia y de fácil comunicación; mientras que, para otro grupo, la imagen que este gobernante proyecte, puede ser de inexperiencia, falta de seriedad y, por ende, incapacidad de gobernar a toda una nación. De esta manera, la imagen recreada por cada ciudadano se formará en base a un sinnúmero de aspectos y atributos que presenta el actor, lo que posteriormente impactará a la imagen de gobierno.

\section{Proceso de formación de la imagen de go- bierno}

La imagen de gobierno se construye a partir de diversos aspectos que mantenga o genere el actor político. La formación de esta imagen contempla tres procesos fundamentales expuestos a continuación: (Figura 1)
I. Identidad de gobierno: se refiere a lo que el gobierno es, su cultura, su esencia. Son los pilares sobre los cuales se creó su ADN.

II. Comunicación de gobierno: está enfocado a lo que el gobierno dice que es; es decir, su identidad transmitida a la ciudadanía. La comunicación de la identidad contempla las diferentes exposiciones, discursos o comunicados que el gobernante y principales funcionarios realiza. Implica todo tipo de hecho comunicativo espontáneo o controlado considerando, por ejemplo, qué es lo que se trasmite, quién lo trasmite, cómo lo transmite o a través de qué medio lo transmite.

III. Imagen de gobierno: lo que los ciudadanos creen que es el gobierno, su identidad percibida. Cada grupo de ciudadanos percibirá la imagen del gobierno de acuerdo a su propio juicio o criterio, y por esta razón, el desarrollo de una adecuada estrategia de comunicación es crucial para que el candidato proyecte con éxito la imagen que desea generar en su público, a partir de su verdadera identidad.

A continuación, veremos dichos procesos con mayor profundidad.

\section{Identidad de gobierno: lo que el gobier- no es.}

La identidad de gobierno, a los fines del presente trabajo, está constituida por tres elementos: el partido de gobierno, el presidente y los principales funcionarios (vicepresidente, ministros de gobierno, entre otros). Estos elementos son cruciales y necesarios al momento de consolidar la identidad de gobierno, pues todos quienes conforman el partido, desde el primer mandatario hasta la asamblea, deben ser capaces de proyectar a los ciudadanos de manera consistente quiénes son. La identidad de gobierno se convierte en el ADN del partido y ese ADN no puede desplegarse o proyectar- 


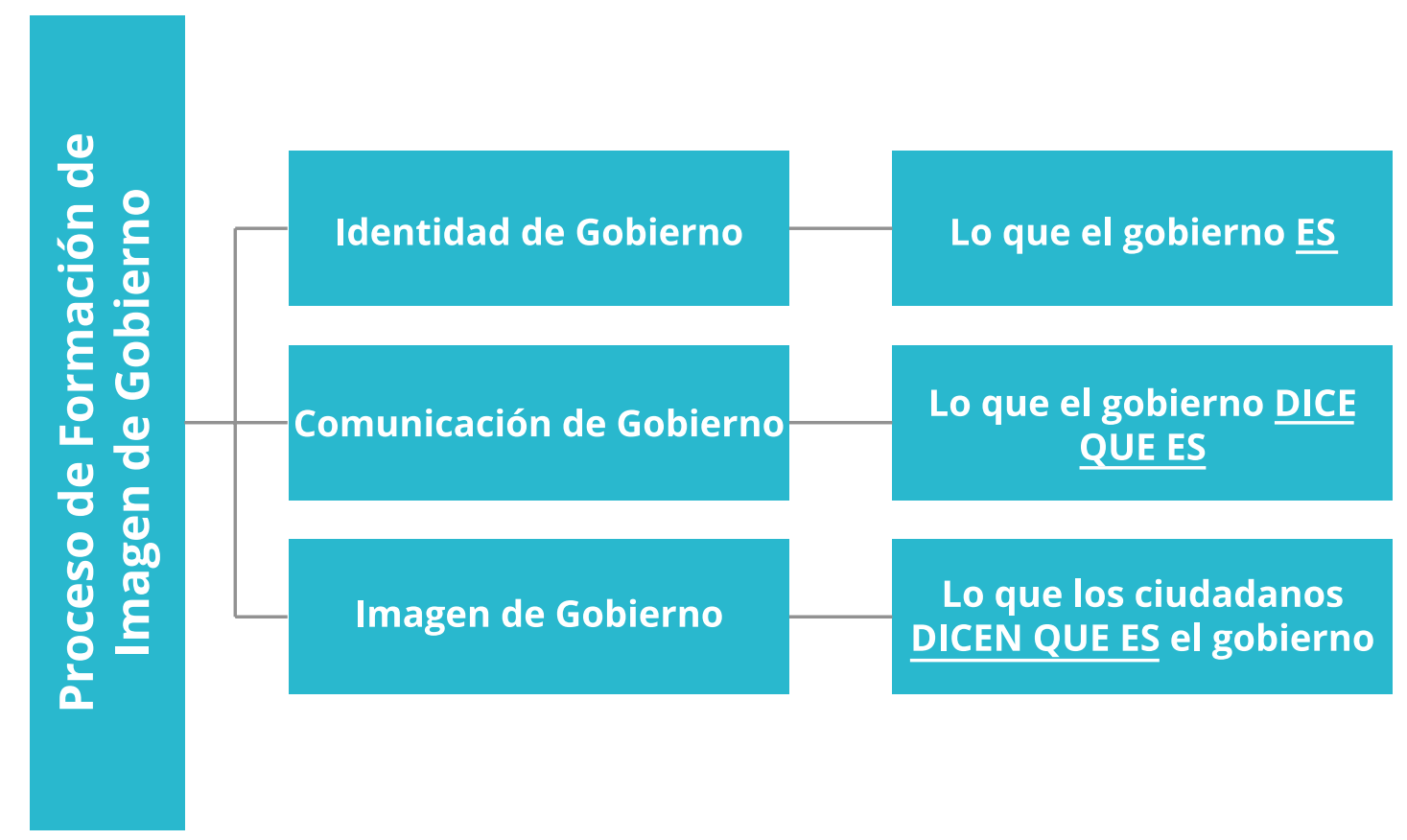

Figura 1. Elaboración propia

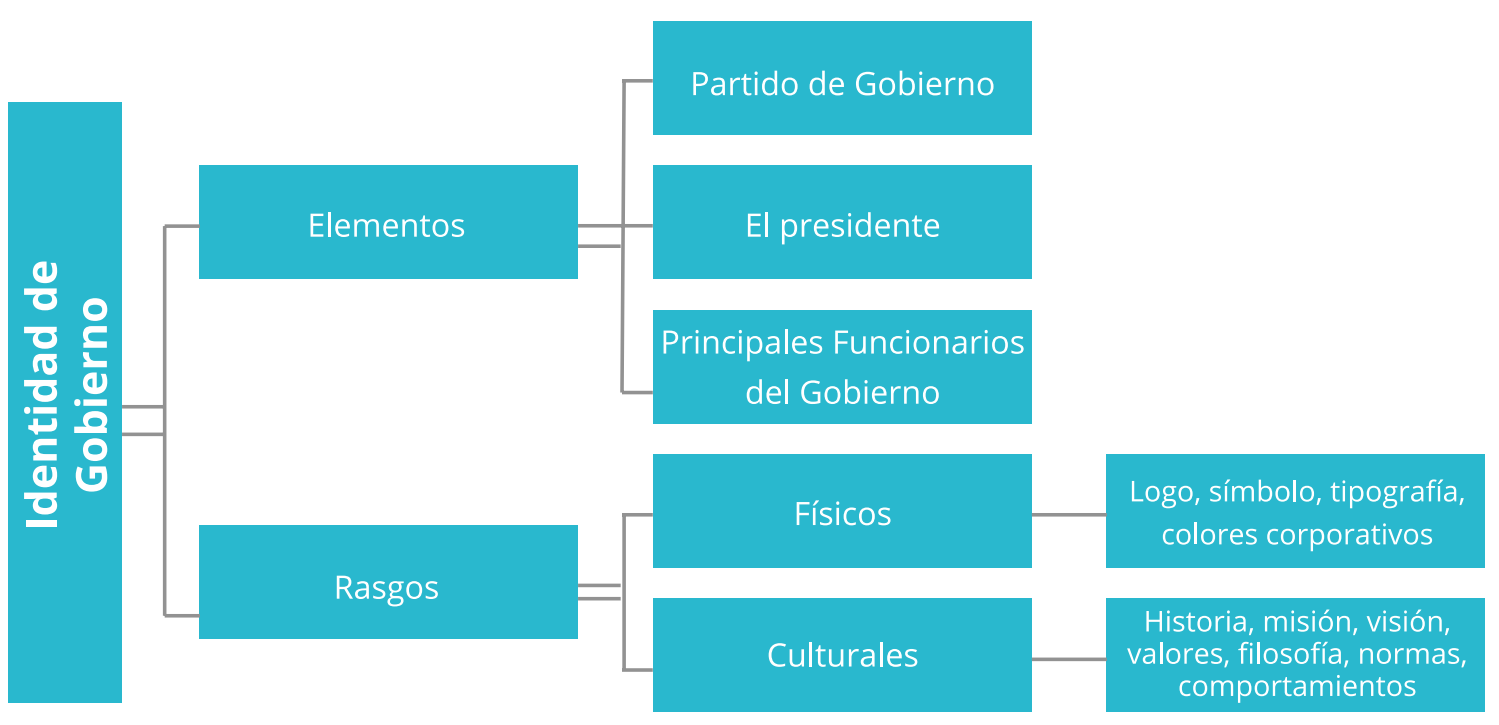

Figura 2. Elaboración propia

se solamente desde el presidente, sino que todos juntos deben marchar sobre un mismo eje y hacia el mismo norte. De otra manera, será un gobierno sin identidad, sin esencia, lo que generará desconfianza hacia los ciudadanos votantes. (Figura 2)

\section{Partido de Gobierno}

Un partido de gobierno es "cualquier grupo político identificado por una etiqueta oficial que se presenta a elecciones, y puede sacar en elecciones (libres o no) candidatos a cargos públicos" (Sartori en Márquez y Fernández, 1997, 
pág. 42), es de vital importancia, como primer paso, determinar su identidad. Dentro de identidad de gobierno, Sánchez Herrera (2009) destaca dos rasgos de la identidad: Los rasgos físicos, que se refieren a aquellos elementos icónico-visuales como signos de identidad válidos para la identificación del partido desde su entorno, como por ejemplo la tipografía, el logotipo, isotipo y colores utilizados. Es decir, todas aquellas cualidades o características que se pueden percibir de forma visual, y que convierte al partido en único. Por otro lado, están los rasgos culturales, que hacen referencia a las creencias y valores del partido, los rasgos de tipo conceptual, ideológico y de comportamiento. Con esto, nos referimos por ejemplo a la tendencia que pueda caracterizar a partidos, izquierda, centro - izquierda, derecha, conservador demócrata; o la conducta y forma de actuar que le ha caracterizado a lo largo de su partido.

Así, todo partido se sostiene de una base ideológica que forma parte de su identidad. Según Sanz de la Tejada (1994), ésta se encuentra fundamentada bajo una concepción filosófica: por un lado, contempla un plano ético, el cual hace referencia a los valores institucionales y la responsabilidad social que la organización desarrolle a favor de la sociedad y/o comunidad; y por otro, un plano cultural, que abarca al conjunto de normas, actuaciones y creencias que se aplican como conducta en una organización. Para poder determinar la identidad de un partido de gobierno, es indispensable identificar los atributos que le otorgarán a éste una singularidad que lo diferenciará de los otros partidos. Estos son: su historia, misión, visión, valores y filosofía. Cabe mencionar que las citas realizadas para cada concepto están analizadas desde una perspectiva organizacional, pero que se considera factible anclarlos al contexto de un partido.
Historia: Es el origen del partido de gobierno, su base. Está en ella personalidad y el espíritu ideológico de sus fundadores. Es importante estar al tanto de la historia del partido, no sólo para poder percibir y determinar su situación actual, sino porque resulta un insumo crucial para el desarrollo de estrategias y toma de decisiones en general, a partir del conocimiento sobre los éxitos o fracasos por los que ha atravesado dicho partido.

La historia de una organización puede comprenderse como un ciclo de vida: que las organizaciones, al igual que las personas, pasan por etapas identificables en su evolución [...] Cada etapa del ciclo de vida de una organización tiene características particulares que ayudan a determinar la personalidad subyacente de la organización. (Lusthaus, 2002, pág. 94)

Misión: Es la función o tarea básica del partido de gobierno. Para ello debe incorporar a su concepto de misión tres aspectos: quién es, qué hace y para quién lo hace; bajo una perspectiva de lo que buscan los ciudadanos. La misión debe ser muy precisa y específica, para poner en evidencia y dejar claro a su público qué es lo que hace y hacia dónde se proyecta. "Constituyen un paso mediante el cual se pone en marcha la visión, la razón de ser de la organización. La misión es una expresión de la manera en que las personas ven el funcionamiento de la organización." (Lusthaus, 2002, pág. 100). Por su parte, Alberto Álvarez define a la misión como "la actividad básica en que se fundamenta la empresa. Responde, por lo tanto, a la definición del tipo de actividad en el cual estará la empresa en el futuro; es la respuesta a las siguientes preguntas: ¿en qué negocio estamos? ¿qué actividad desarrollamos? ¿cuáles son los principios y propósitos inmodificables que guiarán el quehacer de la empresa?" (2004, pág. 117). 
Visión: Es el propósito final al que quiere alcanzar el partido, concentrando sus objetivos y metas para el futuro. La visión debe exponerse de manera clara y explícita hacia dónde se quiere dirigir en un largo plazo, qué tan lejos piensa llegar dentro de un aspecto político, organizacional, entre otros. Editorial Vértice (2008), contribuye al estudio con su propia definición:

La visión de la empresa constituye el conjunto de representaciones, tanto efectivas como relacionales, que un individuo o un grupo de individuos asocian a una empresa o institución como resultado neto de las experiencias, creencias, actitudes, sentimientos e informaciones de dicho grupo de individuos, como reflejo de la cultura de la organización en las percepciones del entorno. (pág. 39)

Valores: Se concentran en principios. Constituyen los rasgos de identidad y señalan la razón de ser del partido y su manera de hacer las cosas. Estos valores y principios deben estar totalmente arraigados al partido e institucionalizados en cada uno de sus miembros condicionando su comportamiento y forma de actuar. "Los valores determinan las conductas, que podríamos considerar como deseables y necesarias en el logro de los resultados. Los valores no deben quedarse en teorías. Para que se legitimen y pasen a formar parte de la cultura, deben ser incorporados a la toma de decisiones y estar presentes en los proyectos de la empresa" (Mateo Campoy, 2007, pág. 41). Los valores institucionales comprenden un conjunto de creencias y concepción de comportamiento, es decir, determinan cómo la institución debe actuar o qué debe a hacer.

Filosofía: Es la explicación de cada uno de los valores y determina el modo de hacer las cosas en el partido. Una visión macro de lo que debe ser el partido y de cuál es su cultura y paráme- tros de conducta. La filosofía determina cómo el partido debe actuar y comportarse según los valores establecidos. "La enunciación explícita de los valores, ayuda al establecimiento de los fundamentos de la filosofía organizacional que sirve de marco referencial para el pensamiento, la toma de decisiones y la acción de los directivos, quienes, además, establecen bases para el aseguramiento de la observancia por todos los miembros de la organización" (Hernández, 2000).

Normas: Son los reglamentos que rigen sobre la estructura organizacional del partido. Estas normas se exponen dentro de un partido de forma escrita y formal, pues señalan el carácter obligatorio: cómo actuar, cómo comportarse, etc. "Las normas indican a los miembros qué deben y qué no deben hacer en ciertas circunstancias [...]. Cuando el grupo acuerda y acepta unas normas, se convierten en medios de influencia de comportamiento de los integrantes con los menores controles externos. (Robbins, 2004, pág. 229). Es importante que cualquier partido político (u organización), sin importar cuál éste fuere, cuente con reglamentos formales, los cuales deben ser acatados y cumplidos por cada uno de los miembros del grupo. De otra forma, se fomentaría una cultura anárquica, en la cual ningún miembro del partido tuviera una dirección de conducta al cual regirse; por ello toda institución tiene o debería tener normas planteadas de manera escrita y formal.

Comportamientos: A diferencia de las normas, los comportamientos hacen referencia a las acciones que no están normadas o regladas, pero que sin lugar a duda constituyen la cultura del partido. "Es el estudio sistemático de los actos y las actitudes que la gente muestra en las organizaciones [...] es una ciencia aplicada de la conducta y, por ello, se apoya en las contribuciones de diversas disciplinas afines, entre las que predominan la psicología, la sociología, 
la psicología social, la antropología y las ciencias políticas" (Robbins y Dávila, 1998, pág. 4). Para la consolidación de la cultura corporativa, resulta clave que el comportamiento de los individuos tenga coherencia con las normas que rige la institución (o partido), pues de otra forma no habría conexión entre ambas esto generaría barreras al momento de proyectar una imagen sólida confiable, capaz de diferenciarse en la mente del público objetivo.

\section{EL PRESIDENTE DE GOBIERNO}

Este actor es el líder máximo del partido y del gobierno, pues bajo su responsabilidad se encuentra toda una nación que deberá respetar y acatar sus disposiciones, mientras éste mantenga su cargo. Para consolidar una identidad propia del Presidente de Gobierno, debemos basarnos bajo la misma premisa de Sánchez Herrera (2009) mencionados ya anteriormente en el partido de gobierno, pero con otros atributos: Los rasgos físicos, en este caso, se refieren a la apariencia y características físicas del presidente de gobierno, su aspecto físico, su vestimenta, accesorios, entre otros. Los rasgos culturales hacen referencia a su perfil biográfico, donde nació, en qué región, su formación y estudios. También incluye el perfil profesional, su carrera política, experiencia, entre otros. Comprendiendo así que "la imagen de un candidato es la sumatoria entre lo físico, lo estético, su historia, sus ideas y hasta lo que los votantes esperan de un "candidato ideal". Todo este conjunto posicionará al candidato con ciertas características que lo harán único y distinguible del resto." (Baeza, 2012, pág. 41)

Adicional a esto, es importante también determinar el grado de conocimiento que tienen los ciudadanos del presidente; es decir, su nivel de posicionamiento. ¿Cómo estos lo perciben?, ¿cuántos saben de él?, ¿qué saben de él?, entre otros, son cuestionamientos que nos ayudarán a determinar los datos necesarios para tener un perfil claro de identidad del mismo. Es preciso tomar como punto de partida una recopilación completa de la investigación y los resultados que lo llevaron a ganar la campaña electoral, pues estos datos son indicadores base para consolidar y posicionar a un gobierno. Es decir, se debe determinar qué lo llevó a ser presidente, qué elementos lo hicieron ganador. Si se trata de una campaña electoral diseñada y ejecutada de forma estratégica, técnica y objetiva, tendrá una gran cantidad de información bien estudiada y procesada. Si, por el contrario, se trata de una campaña improvisada, habrá que averiguar qué es lo que sus electores creyeron que decía. Este proceso de análisis, parte de una investigación de carácter tanto cualitativo como cuantitativo y de esta interpretación dependerá el adecuado o inadecuado uso, planeación, diseño, desarrollo y ejecución del plan estratégico para el presidente.

De la misma forma, se requerirá realizar un estudio a profundidad sobre la presencia en medios masivos y digitales del Presidente, para poder definir con claridad en qué medios se desenvuelve mejor. Este estudio nos ayudará a saber a qué terreno llevarlo con confianza y qué terreno evitar.

Los massmedia ampliaron la esfera de lo público y expusieron el quehacer político a la mirada múltiple de las audiencias, con ello transformaron la concepción tradicional del vocablo poder, para convertirlo en el poder mediático. (Chomsky, 1990). La televisión, por ejemplo, al ser un medio audiovisual, tiene mayor oportunidad de interceder en la percepción del público con respecto a la imagen del actor político; sea positiva o negativa. "Teniendo en cuenta que es a través de las noticias como el público se informa, lo que los medios dirán será la base 
de la imagen mental de lo que está sucediendo. En consecuencia, los medios tienen la capacidad de dirigir la atención pública hacia ciertos temas, efecto que se denomina agenda-setting o "establecimiento de la agenda". (Baeza, 2012).

Vinculado a esto es clave el análisis del manejo del lenguaje audiovisual del presidente de gobierno. A través del análisis del lenguaje verbal podremos conocer y analizar el contenido y estilo de sus mensajes. Por otro lado, a través del análisis del lenguaje no verbal, conoceremos los aspectos que tienen que ver con la forma en la que el presidente emite sus mensajes. En este sentido, las cualidades de la voz (volumen, velocidad, entonación, vocalización, ritmo, fluidez y pausas) son características claves a considerar en la descripción y análisis en el perfil del presidente. El lenguaje corporal, que incluye: gestos, posiciones, distancias y movimientos del cuerpo. Finalmente, la forma de vestir, el estilo, y los accesorios que porte la figura, son otro aspecto importante a considerar. En este sentido, es importante destacar que los procesos verbales y no verbales son interdependientes y la combinación de ambos consolidan la identidad del Presidente de Gobierno.

Con todos estos elementos analizados podremos realizar un análisis de las fortalezas, oportunidades, debilidades y amenazas (FODA) del actor político, el cual "es una herramienta de carácter gerencial válida para las organizaciones privadas y públicas, que facilita la evaluación situacional de la organización y determina los factores que influyen y exigen desde el exterior hacia la institución" (Burbano, 2005, pág. 85). "Una de las aplicaciones del análisis FODA es la de determinar los factores que pueden favorecer (fortalezas y oportunidades) u obstaculizar (debilidades y amenazas) el logro de los objetivos establecidos con anterioridad para la empresa" (El Plan de marketing, 1988, pág. 158). Con este análisis se tendrá un mapa objetivo de la situación actual y se podrá determinar de manera efectiva las fortalezas y debilidades tanto personales como profesionales del Presidente.

\section{PRINCIPALES FUNCIONARIOS}

El vicepresidente y ministros son parte de la imagen del gobierno. Estos son personajes que desempeñan importantes funciones para el gobierno y, por lo tanto, contribuyen para bien o para mal en la construcción de su imagen.

El presidente, por lo tanto, debe tener a todos sus funcionarios totalmente alineados y bajo una misma orientación. No puede caber la posibilidad de tener en el equipo del partido de gobierno a un ministro o funcionario que pueda perjudicar al mismo. Es arriesgar demasiado la identidad del partido y, por ende, su imagen. Es por ello que debemos investigar a los principales funcionarios; para en función de ello establecer lineamientos estratégicos de comunicación que contribuirán a edificar y consolidar la identidad del presidente.

En primer lugar, debemos saber cuánta gente conoce a los principales funcionarios y si su imagen es buena o mala; es decir, investigar el alcance y el nivel de posicionamiento que tienen estos personajes, y con estos datos realizar un análisis de diagnóstico para poder determinar en qué porcentaje del universo estudiado es positiva o negativa la imagen que perciben los ciudadanos de los funcionarios. En segundo lugar, es preciso tener un claro conocimiento sobre las áreas que manejan los funcionarios y su capacidad de influencia. En tercer lugar, conocer desde la estrategia qué rol van a desempeñar en el gobierno. 
Tabla 1.

\begin{tabular}{|c|c|}
\hline Actores Políticos & Elementos a analizar \\
\hline $\begin{array}{l}\text { Presidente de gobierno } \\
\qquad \text { Vicepresidente } \\
\text { Principales Funcionarios }\end{array}$ & $\begin{array}{c}\text { - Perfil personal } \\
\text { · Perfil biográfico } \\
\text { - Trayectoria política } \\
\text { - Aspectos que lo llevaron a ganar las elecciones } \\
\text { • Presencia en medios masivos } \\
\text { - Presencia en medios digitales } \\
\text { - Lenguaje verbal: discurso y contenido } \\
\text { • Lenguaje no verbal }\end{array}$ \\
\hline
\end{tabular}

II. Comunicación de gobierno: lo que el gobierno dice que es. Su identidad transmitida.

\section{- La comunicación de gobierno}

La comunicación gubernamental o de gobierno es aquella que se transmite desde el Gobierno hacia sus diferentes públicos a través de comunicados formales. Según Daniel Ivoskus "tiene como objetivo ganar la simpatía, confianza, credibilidad, preferencia y buena voluntad de los gobernados. Sin embargo, la principal dificultad que enfrenta consiste en orientarse a grandes grupos de personas que presentan rasgos generales en su conjunto, pero la individualidad de las personas que la integran sigue encerrando diferencias" (2010, pág. 75.). La comunicación de gobierno es una herramienta de vital importancia; de hecho, se remonta desde los orígenes de la historia humana, cuando las personas ideaban diferentes formas de comunicarse los unos con los otros para expresarse, convocarse, dar señales de alerta, etc. Existe un sinnúmero de definiciones de comunicación; sin embargo, se mencionará uno de ellos, el cual servirá como insumo para contribuir a una mejor comprensión sobre este punto: "el proceso a través del cual una persona o personas transmiten a otra u otras, y por cualquier procedimiento, mensajes de contenido diverso, utilizando intencionadamente signos dotados de sentido para ambas partes, y por el que se establece una relación que produce unos efectos". (Hervás, 1998, p.12)

Como hemos visto, la comunicación es una herramienta extremadamente importante dentro del marco político. Específicamente, sin comunicación no es posible transmitir la identidad. Cabe mencionar que la comunicación de gobierno engloba todo lo que éste comunica, con sus acciones y omisiones, con lo que dice y deja de decir. Recordemos una vez más, que el gobierno no comunica únicamente en sus discursos políticos, o cuando se dirige verbalmente a los ciudadanos durante cualquier otra situación, la omisión también comunica, por ende, también contribuye a construir la percepción que reciben los ciudadanos. En este sentido hay dos conceptos que se interrelacionan con la comunicación el "storytelling", que se refiere a la estrategia de comunicación, "lo que digo que hago"; lo que el Presidente cuenta a sus públicos con el fin de generar empatía. "El "storytelling" es en realidad una forma de denominar lo que siempre hemos llamado relato o narrativa. Dese la prehistoria, los líderes trabajan contando con palabras, con sonidos y con imágenes..." (Gutiérrez, Rodríguez and López, 2014). Por el contrario, el "storydoing", representa a la estra- 
tegia de acción, y es "lo que realmente hago", se refiere a "un legado vital mucho más interesante que una simple "historia" o una campaña creativa o notoria..." (León Delgado et al., 2014)

Los ciudadanos ya no se conforman con solamente escuchar, sino que ahora manifiestan su interés y poder en ver, vivir, experimentar, palpar lo que el Presidente y sus funcionarios están comunicando. En este sentido, Foucault dice que: "El poder transita transversalmente, no está quieto en los individuos" (1991, pág. 144). El poder circula, funciona en cadena y se manifiesta en los ciudadanos. La comunicación puede ser una herramienta muy poderosa, pero no milagrosa. Si no hago lo que digo, por más bien diseñada que esté la estrategia de comunicación, ésta carecerá de efectividad. Por eso, es importante que un actor político, al igual que los otros miembros de su partido de gobierno, no se queden con el storytelling, sino que den un salto al storydoing; "El relato, la narrativa no sólo hay que contarla, sino, sobre todo, interpretarla y hacerla real. La política, es decir, pero también y, sobre todo, hacer. El storytelling está muy bien, pero es mejor el storydoing" (Gutiérrez, Rodríguez and López, 2014); así sembrarán confianza y proyectarán una imagen positiva a los ciudadanos.

Otro aspecto relevante de la comunicación de gobierno es la retroalimentación a sus ciudadanos con la finalidad de comunicar lo que ha hecho, sus planes a ejecutar, etc. Es decir, no solo debe decir que va a hacer, sino dar un seguimiento y cumplir con lo que dice, al mismo tiempo de comunicar con absoluta veracidad cada acción que realice. "La clave es parte importante del éxito en una campaña propagandística política está en que nuestros mensajes de calidad y contenido aterricen en la mente del público y estén dotados de veracidad, intención franqueza y sean viables no ofreciendo ninguna duda, así como que tengan contenido y calidad humana." (Barquero Cabrero u. a., 2005, pág. 19)

\section{- La estrategia de comunicación}

Para elaborar la estrategia de comunicación se necesita partir de la interpretación de los datos obtenidos en la investigación sobre el presidente, el partido y los funcionarios. Adicionalmente, se debe contar con un calendario en el que constan las acciones y eventos más importantes que va a protagonizar el gobierno en su período. Ese calendario supone un plan de acción: el gobierno debe ubicar a lo largo de su período las acciones que va a realizar en las diversas esferas. De esas acciones algunas serán utilizadas como ejes de comunicación de acuerdo a la estrategia. Por lo tanto, la agenda del presidente es el principal mensaje: a qué dedica tiempo, a quiénes ve, en dónde está, etc. "Ya no se puede ser eficiente dando saltos improvisados, se necesita de una estrategia. Esa forma de ver todos los elementos de la guerra integrados e interactuando entre sí es útil en la política. Por eso, muchos plantean la estrategia de comunicación como un plan de guerra y usan una serie de términos militares para analizarla" (Ferreiro, 2016)

Cuando un gobierno carece de estrategia de comunicación, envía mensajes a diestra y siniestra y reduce la comunicación al plano táctico; es decir que se limita a transmitir información, sin contar con una previa planificación estratégica.

Estrategia [...] implica planear, organizar y dirigir nuestras actuaciones, en las diferentes fases del proceso comunicativo, para luego examinarlas, verificarlas y evaluarlas, tratando de aprender tanto de los errores o problemas como de factores de éxito. (Fonseca Yerena and Gaona Figueroa, 2005) 
El diseño de una estrategia debe contemplar un mensaje determinado que tenga unidad conceptual. Además, debe haber una conexión entre el mensaje y los grupos objetivos. En otras palabras, se debe generar la misma idea adaptada a su propio lenguaje, según el perfil y las características de los ciudadanos.

\section{Imagen de gobierno: Lo que los ciuda- danos creen que es el gobierno. Es identi- dad percibida.}

El proceso de formación de la imagen culmina justamente con la imagen de gobierno propiamente dicha, que es cómo los ciudadanos perciben al mismo. "El cuidado de la imagen pública es un arte, el arte de comunicar eficazmente lo que usted es y lo que quiere ser.... Lo primero que debe sintonizar en su interior, es que su imagen es como tener un banco. Mejor imagen, mayor poder de influencia; mejor imagen, mayor credibilidad. Buena imagen es puntos para su banco de imagen, mientras más puntos más votos". (Corral, 2007, pág. 23) En este sentido, si la identidad de gobierno coincide con lo que los ciudadanos piensan del mismo, es porque el proceso de formación de la imagen ha sido exitoso y la comunicación establecida ha contribuido a posicionar adecuadamente la gestión del gobierno.

\section{CONCLUSIONES}

Un candidato político no necesita solamente dinero para llevar a cabo una gran y exitosa campaña, sino que además requiere de una imagen estratégica y positiva, de persuadir y convencer a los ciudadanos que voten por él. La consolidación de una imagen política positiva viene a ser ese ingrediente intangible que determina el apoyo o no de los ciudadanos, pues es capaz de otorgar al partido una buena dosis de carisma, brillo, autenticidad, credibilidad y poder de seducción. Esa imagen positiva debe trasladarse de manera sistemática a la comunicación de gobierno.

La construcción de la imagen es un proceso que se forma a partir de la identidad y la comunicación. Primero de la identidad, pues de otra forma no tendríamos qué comunicar a nuestra audiencia. La identidad política parte de la esencia del partido, de su inclinación ideológica, su filosofía, su comportamiento; y por supuesto, su historia. Su trayectoria no es lo único que definirá su identidad, sino también, el perfil personal de cada uno de los integrantes del gobierno. Una vez definida su identidad, la comunicamos. La comunicación es una parte vital en el proceso de construcción de la imagen, porque de ésta depende la opinión que los ciudadanos se formen del candidato.

La comunicación debe considerar aspectos verbales y no verbales, y controlar que el storydoing se convierta en una característica del candidato. Un político jamás ganará seguidores si se dirige a los ciudadanos con palabras vacías, sin fondo ni realidad, al contrario, los perderá. Como ciudadanos, estamos atentos a todo lo que dice, pero también a todo lo que hace; así que de nada le servirá al candidato un discurso lleno de lindas palabras, si en su 
actuar diario se contradice y no muestra consistencia al respecto. Es importante hacer lo que se predica. Y dentro de este concepto, se debe cuidar que el story-telling lo maneje cada uno de los miembros, pues hay que considerar que el candidato no está solo, lo acompaña un equipo de Gobierno.

Así, con la consolidación de la identidad de gobierno acompañado de una comunicación estratégica, se edificará la imagen deseada del mismo, alineada efectivamente a los respectivos objetivos los cuales habremos planteado previamente en nuestro plan de gestión. Esto, generará empatía hacia los ciudadanos y por ende su apoyo y respaldo. Sin embargo, hay que recalcar que la imagen de gobierno, como cualquier otra, puede ser una montaña rusa, con sus altos y sus bajos; puesto que puede alterarse a medida que van transmitiendo la gestión de gobierno. Esto sin duda se convierte en una desventaja, por lo que a lo que debemos apuntar es mantenerla en lo alto; es decir, que la percepción de los ciudadanos con respecto al gobierno sea positiva de manera continua y permanente. Entonces empezaríamos a construir una reputación de gobierno, objeto de estudio presto a una próxima reflexión. 


\section{BIBLIOGRAFÍA}

Acanda, Jorge Luis (2002), Sociedad civil y hegemonía, Centro de Investigaciones y Desarrollo de la Cultura Cubana "Juan Marinello", Cuba.

Álvarez Cardona, A. (2004). Administración de maquinaria agrícola. Medellin: Universidad Nacional de Colombia.

Baeza, N. S. (2012). Cómo se construyó el candidato: Un estudio de caso sobre Imagen Política. (Trabajo final de grado). Universidad Nacional de La Plata. Facultad de Humanidades y Ciencias de la Educación. En Memoria Académica. Disponible en: http://www.memoria.fahce.unlp.edu.ar/ tesis/te.836/te.836.pdf

Barquero Cabrero, José Daniel; Xifra i Triadú, Jordi; Barquero Cabrero, Mario u. a. (2005): Gane usted las próximas elecciones. Barcelona: Gestión 2000.

Burbano Ruiz, J. (2005). Presupuestos. Colombia: McGraw-Hill Interamericana.

Campoy, Daniel (2007): Cómo gestionar y planificar un proyecto en la empresa. [Vigo]: Ideaspropias.

Capriotti, Paul. (1992). La imagen de empresa: estrategia para una comunicación integrada. España: El Ateneo

Chomsky, Noam y Edward S. Herman (1990), Los guardianes de la libertad. Propaganda, desinformación y consenso en los medios de comunicación de masas, Grijalbo-Mondadari, España

Corral, María Sol (2007): El candidato perfecto. Ecuador: Paradiso.

Costa, J. (2003). Imagen Corporativa en el Siglo XXI. Buenos Aires: La Crujia.

Dirección estratégica. (2008). Málaga: Vértice.

El Plan de marketing. (1988). Madrid: Díaz de Santos.

Ferreiro, C. (2016). Estrategias de Comunicación para Gobiernos. Ejemplo deBarack Obama. [online] Recuperado en: https://estrategiasdecomunicacionalumnosucm.files.wordpress.com/2012/02/estrategias-de-comunicacion-para-gobiernos.pdf [Recuperado el 2 Apr. 2016].

Fonseca, Socorro (2000): Comunicación Oral Fundamentos y Práctica Estratégica. (1era Ed.). México: Pearso Educación 
Foucault, Michel (1991), Microfísica del poder, La Piqueta, España.

Hernández, J. (2000). La culturocracia organizacional en México. B - EUMED.

IND, Nicholas. (1990). La Imagen Corporativa: Estrategias para Desarrollar Programas de Identidad. Madrid: Diaz de Santos.

Ivoskus, D. (2010). Cumbre Mundial de Comunicación Política. Buenos Aires, Argentina: Libros del Zorzal.

Lusthaus, C. (2002). Evaluación organizacional. Washington, D.C.: Banco Interamericano de Desarollo.

Mella Márquez, M. and Abreu Fernández, V. (1997). Curso de partidos políticos. Torrejón de Ardoz, Madrid, España: Ediciones Akal.

Robbins, S. (2004). Comportamiento organizacional. México, D.F.: Pearson.

Robbins, S. and Dávila Martínez, J. (1998). Fundamentos de comportamiento organizacional. México: Prentice Hall.

Sanz de la Tejada, Luis (1994). Integración de la identidad y la imagen de la empresa: desarrollo conceptual y aplicación práctica. Madrid: ESIC

Sánchez Herrera, Joaquín (2009): La creación de un sistema de evaluación estratégica de la empresa aplicable a las decisiones de inversión en mercados financieros. Madrid: ESIC. 